\title{
Assessing urban sprawl by remote sensing and GIS techniques
}

\author{
Mohamed El-Sayed Embaby * \\ National water research center, Cairo, Egypt. \\ Global Journal of Engineering and Technology Advances, 2021, 07(03), 144-156
}

Publication history: Received on 13 May 2021; revised on 18 June 2021; accepted on 21 June 2021

Article DOI: https://doi.org/10.30574/gjeta.2021.7.3.0088

\begin{abstract}
In the context of mega sustainable urban development projects, this research was commenced with the impartial of assessing urban sprawl (i.e., land use versus land cover variations) during 2000-2016 by remote sensing and GIS techniques, where GCR "Greater Cairo Region" was taken as a case study. Primarily, literature in the field of remote sensing and GIS technologies were assembled and scrutinized. In addition, data regarding build zones, agricultural areas and bare soil regions so as water were assembled from different resources (i.e., Ministry of Agriculture). Remote sensing and GIS techniques were implemented. Results were obtained and analyzed. Finally, conclusions were deduced and recommendations were suggested. The research flagged-out that the GCR designated a drastic agriculture land loss of $10 \%$. In addition, the research confirmed that built-up areas increased by $10 \%$ during 2000-2016. On the other hand, the results indicated that Giza and Qalyubia Governorates recorded the largest agriculture land loss by 8.72 and $7.88 \%$, respectively, which is equivalent to 47 and $77 \mathrm{~km}^{2}$, respectively. The research prioritized the importance of defining the most affected zones within Giza and Qalyubia Governorates by correlating GIS data versus governmental files, where a difference of $50 \%$ was designated. The research portrayed the priority of modifying the government assessment approach in order to control urban sprawl.
\end{abstract}

Keywords: Land-Use Land-Cover variations (LULC); Geographic Information System (GIS); Remote Sensing; Urbanization; Urban sprawl; Water Quality; Greater Cairo Region

\section{Introduction}

Urban settlements are lured to sprawl after promising prosperity that attracts most settlers. Urban sprawl "U.S." is an urban encroachment and it is an unrestricted growth in urban areas of housing or commercial development with little concern to urban planning. U.S. denotes dynamic unplanned spread and it is an unplanned informal development. Sprawl is a form of urbanization that relates this development to the social so environmental consequences. Sprawl is measured by the number of residential elements/acres.

Sprawl entailed disadvantages that include increased travel time, extra transport costs and pollution. It is a leapfrogging-development. It has negative implications such as environmental degradation that destroys the visual appealing of places. The term prioritizes the importance of managing urban growth.

Accordingly, literature in the field of remote sensing and GIS technologies were assembled and scrutinized, where it was apparent that many researchers are involved in investigating U.S.

For example, Cities blend the low-income citizens into the national economy documented in Urban Sprawl (1). In addition, domestic migration result in expansion of cities with developing economies documented in the world urbanization prospects (2). Furthermore, highlight that $50 \%$ of the world's population lives in urban areas and this ratio

${ }^{*}$ Corresponding author: Mohamed El-Sayed Embaby; Email: m_moh1979@yahoo.com

Researcher, National water research center, Cairo, Egypt

Copyright (C) 2021 Author(s) retain the copyright of this article. This article is published under the terms of the Creative Commons Attribution Liscense 4.0. 
will be $66 \%$ in 2050 (1). Moreover, City growth is a planned development and it is a natural element of the life of a city like, for example, Barcelona experienced several expansions during 1865-2004 and Bahir Dar witnessed several expansions during 1965-2013 (2). Similarly, U.S. could be legal, in terms of private landowners that have right to build their land (3). For example, in UK planning permission is needed for farms, if landowners wish to change land use, while in other counties planning permissions are required for building on non-agricultural lands. Furthermore, Reforms cause population to be doubled within half a century (4).

The area of the lost Egyptian agricultural lands during the period (1983-2005) reached about 93.697 thousand feddans during that period, of which about 46.970 thousand feddans (i.e. about $50.1 \%$ of the total urbanized land) has been built on, and 38.2 thousand feddans (about 46.8) were left for a long period without agriculture as a preparation for urbanization although all agricultural parameters were available, and 8.52 thousand feddans (about 10.1\%) were used in other agricultural industrial and storage activities. From January 25 to February 8, 2011, there were 31.128 cases of encroachment on the agricultural lands in various governorates (5).

However, in 1907, 17.2\% of Egypt's population were living in urban centers according central agency for public mobilization and statistics (6). This ratio increased to 43-57\%. During the period from January 2011 until November 2014 , the number of violations reached about 1.242 million cases, with an area estimated at 54.251 thousand feddans. About 69.249 thousand feddans were removed, or about $17 \%$ of the total area of the violations. This area was distributed over all governorates of the Republic without exception, as the governorates of Lower Egypt occupied the first place among the governorates of Egypt, with a rate of violations amounting to about 56.7\% of the total volume of violations during this period, followed by the governorates of Upper Egypt with about 10,450 feddans equivalent to about $19.2 \%$ of the total number of violations that occurred during that period, and Al-Gharbia governorate occupied the highest percentage of violations, reaching about 5.556 feddans, or about $10.24 \%$ of the total number of the violations, followed by Al-Buhaira governorate with about 5.474 feddans, representing about $10.1 \%$ of the total number of the violations, then the governorates of Dakahlia and Sharkia, by about $8.8 \%$ and $8 \%$, respectively, and the new wadi governorates recorded the least governorate, as the violations amounted to about 3 feddans as shown in table.

Accordingly, in the context of mega sustainable urban development projects, this research was initiated with the objective of evaluating urban sprawl during 2000-2016 by remote sensing and GIS, where GCR was taken as a case study.

\section{Data Assembly}

Data regarding build zones, agricultural areas and bare soil regions so as water bodies were assembled from different resources (i.e., Ministry of Agriculture, Egyptian Survey Authority and General Organization for Physical Planning 2018) to the study area GCR "Greater Cairo Region"; figure (1). GCR encompasses 3 governorates (i.e., Cairo, Giza and Qalyoubia). Its area is $40,571 \mathrm{~km}^{2}$, where this research limits the studies to the rural urban fringe of GRC; figure (1).

From the assembled data, the following was clear:

- $\quad$ The planning process in Egypt splits the country into seven economic regions that are divided into 27 governorates (7).

- $\quad$ Three zones were distinguished (i.e., governorate, urban governorate, mixed governorate and marakiz).

Their descriptions are as follows:

- A governorate might encompass urban and rural or only urban characteristics.

- An urban governorate includes cities and neighborhoods (i.e., Cairo is an urban governorate. It contains Cairo City and 35 neighborhoods).

- A markaz is split into cities, neighborhoods, mother villages and villages (7).

- A mixed governorate encompasses marakiz (i.e., Giza is a mixed governorate it includes 8 marakiz, 13 cities and 7 neighborhoods. Also, Qalyoubia is a mixed governorate with 7 marakiz and 10 cities (8). 

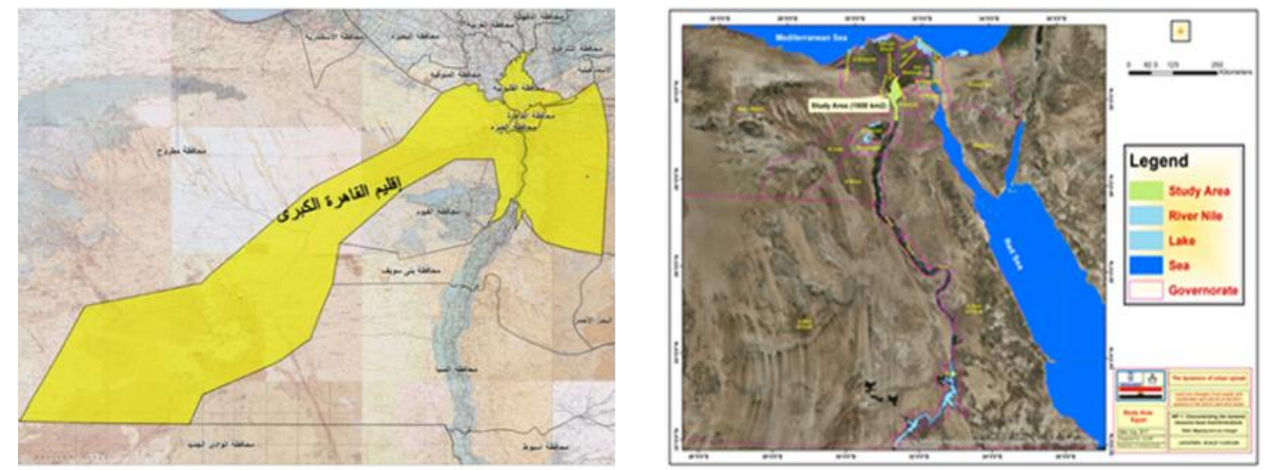

Figure 1 Official Government Boundary of GCR and selected study area General Organization for Physical Planning 2018

\section{Implementing Satellite Images and GIS Techniques}

After assembling the required data from the different resources, satellite images and GIS techniques were implemented. This was achieved in order to assess the changes in land-use and land-cover (LULC) during 2000-2016, where the satellite images included 5 Landsat images that were obtained from Landsat-7 ETM+ "Enhanced Thematic Mapper Plus" and Landsat-8 OLI "Operational Land Imager" during 2000-2016.

It is to be noted that time series of Landsat images were acquired during summer seasons. They were available in the Landsat archive, USGS "United States Geological Survey" (9). In addition, during the implementation, all visible and infrared bands were included. Moreover, the topographic maps were used for ground authentication and geometric correction for the satellite images.

\subsection{Image Pre-Processing and Enhancement}

During the satellite image and GIS implementation, images were re-processed and enhanced, as follows:

\subsubsection{Pre-processing of satellite images}

Pre-processing of satellite images was achieved before changing the detection. It intends to establish a direct linkage between data and biophysical phenomena (10). Image pre-processing operations included 4 activities (i.e. geometric correction, ETM + gap filling, image enhancement and interpretation).

- The implemented images during 2000-2016 were corrected geometrically to 2016 by RMSE "root mean square error", which is less than 0.5 pixels. 2016 image was geo-referenced to ground points so as topographic maps, where its RMSE is less than 0.3 pixels.

- Geometric correction was achieved, as it is important for digital change detection, where PCC does not need the images to be radio-metrically normalized or corrected before being implemented for detection of change (11).

- $\quad$ Recent LULC maps were obtained from Landsat data, where SLC (scan-line corrector) failed in 2003.

- SLC failure resulted in un-scanning of $20 \%$ of the pixels in an ETM + image (12).

- Composite data from adjacent scenes were assembled from Landsat 7 data. This is attributed to the fact that missing data of SLC anomaly could be replaced by overlapping adjacent scenes (i.e., lateral overlapping) or by passing over the same scene (i.e., same images from other dates).

- Gaps were filled for ETM + 2006 image, where a lateral ETM + of July 2006 scene was implemented.

- Gaps were filled based on the same scene in July 2002.

\subsubsection{Image enhancement}

Image enhancement was achieved to improve its visual interpretability by increasing the distinction between topographies. This was done to modify the image to recognize information.

Visual analyses were performed to the enhanced images. Automated analyses were performed to original images (13), (14). Contrast stretching was achieved to 5 images and was visually interpreted. 
LULC features were grouped into 4 types. These are:

- Bare soil (barren land)

- Agricultural lands

- Urban lands

- Water bodies

Based on visual interpretation of the satellite imagery, 4 types were identified. The 4 types were verified against field inspection.

- $\quad$ Barren land is land without vegetation (i.e., desert or brownfield sites).

- Agricultural lands are land cultivated with crops or fruit trees.

- Urban areas encompass cities, rural villages and infrastructure.

- Water areas include water zones.

Enhanced images were visually interpreted via screen digitalizing to delineate LULC classes (i.e. urban, water bodies, bare soil and agricultural land).

\subsection{Classification of Land Uses}

After image pre-processing and enhancement, land uses were classified, where the following was achieved:

- $\quad$ ENVI 5.3 software was tooled for processing the digital image of Landsat images.

- Training samples were carefully chosen for pre-determined LULC types by delimiting polygons around sites.

- The enclosed pixels of the polygons were derived according to the land cover type.

- A spectral signature is satisfactory when land covers are mapped with minimal confusion (15).

- Classification process was achieved after reaching a satisfactory spectral signature, where SupervisedMaximum-Likelihood-Method.

- A thematic raster layer (the classified image) and a distance file were obtained from the classification process.

- Post-classification thresh was held for the distance file.

- Some LULC classes could not be identified, for example:

Urban class was overvalued in LULC maps, as $85 \%$ of the irrigation network is concrete. Green landscapes experienced overestimation.

- Classification accuracy was improved. The obtained LULC maps were integrated with visual interpretation maps by overlay operation with ArcGIS 10.4 software (16).

- Accurate LULC maps were produced and compared to reference data in order to assess the classification accuracy (17).

- $\quad$ Classification accuracy was evaluated based on 280 random points by Envi software.

- $\quad$ The 280 points represent field checkpoints.

- The reference data and classification results were equated and analyzed via error matrices.

- 3 change maps were assembled to represent the nature of changes in the classified images.

\section{Results and discussion}

Confident with the obtained results, they were analyzed and discussed, in terms of LULC changes, LULC changes in the three governorates, analyzed results verification and the official sprawl data, as follows:

\subsection{Land-Use and Land-Cover (LUCL) Changes}

Focusing on the obtained data, regarding the LUCL changes, they were analyzed and presented in tables, graphs so as maps (i.e., tables (1) and (2) together with figures (2) and (3)). These are discussed here, where they designated that:

- GCR experienced significant changes, where the most visible changes are related to agriculture land and builtup areas increase.

- Significant changes occurred during 2002-2006 and 2006-2014, where agriculture land dropped to $61 \mathrm{~km}^{2}$ and $67 \mathrm{~km}^{2}$. 
- GCR lost $7.47 \%$ of its agricultural land in one decade and half.

- $\quad$ The built-up area increased and $199 \mathrm{~km}^{2}$ were added to GRC in 2000-2016 (i.e., 10.41\%).

- Population growth, economic development and political instability are the factors that might explain the drastic increase in real estate development, where the population of GCR was 17.7 and 22.6 million in 2006 and 2016 , respectively, (6).

- U.S. is the reason behind built-up area increase and decrease in agriculture land.

- In urban centers, sprawl is affected by demographic factors.

- During 2004-2016, the population of the 3 governorates rose by 1.9, 2.4 million and 1.5 million respectively (6).

- $\quad$ Life span increased by two years during 2000 - 2016.

- Divorce rate increased and affected the household needs.

- Migration promotes sprawl. It increased to 1.2 million during 1996-2006. CAPMAS attributed this migration to work, study, marriage requirements.

- With workers, students and citizens invasions, housing demands exceeded the supply.

- Economic factors are drivers of sprawl such as value of crops related to the fertilizers prices (18).

- Inflation encourages Egyptians to solidify money in real estate, which increases sprawl.

Table 1 Changes in area of GCR $\left(\mathrm{Km}^{2}\right)$

\begin{tabular}{|l|c|c|c|c|}
\hline Years & $\mathbf{2 0 0 0 - 2 0 0 2}$ & $\mathbf{2 0 0 2 - 2 0 0 6}$ & $\mathbf{2 0 0 6 - 2 0 1 4}$ & $\mathbf{2 0 1 4 - 2 0 1 6}$ \\
\hline Agriculture & -13 & -61 & -50 & -17 \\
\hline Bare soil & 7 & -70 & -2 & 8 \\
\hline Built-up & 8 & 127 & 52 & 12 \\
\hline Water & -2 & 4 & 0 & -3 \\
\hline
\end{tabular}

Note: -ve sign designates area decrease

Table 2 Area change in percentage

\begin{tabular}{|l|c|c|c|c|}
\hline Years & $\mathbf{2 0 0 0 - 2 0 0 2}$ & $\mathbf{2 0 0 2 - 2 0 0 6}$ & $\mathbf{2 0 0 6 - 2 0 1 4}$ & $\mathbf{2 0 1 4 - 2 0 1 6}$ \\
\hline Agriculture & -0.69 & -3.16 & -2.69 & -0.85 \\
\hline Bare soil & 0.37 & -3.74 & -0.25 & 0.56 \\
\hline Built-up & 0.43 & 6.72 & 2.93 & 0.42 \\
\hline Water & -0.11 & 0.18 & 0.01 & -0.13 \\
\hline
\end{tabular}

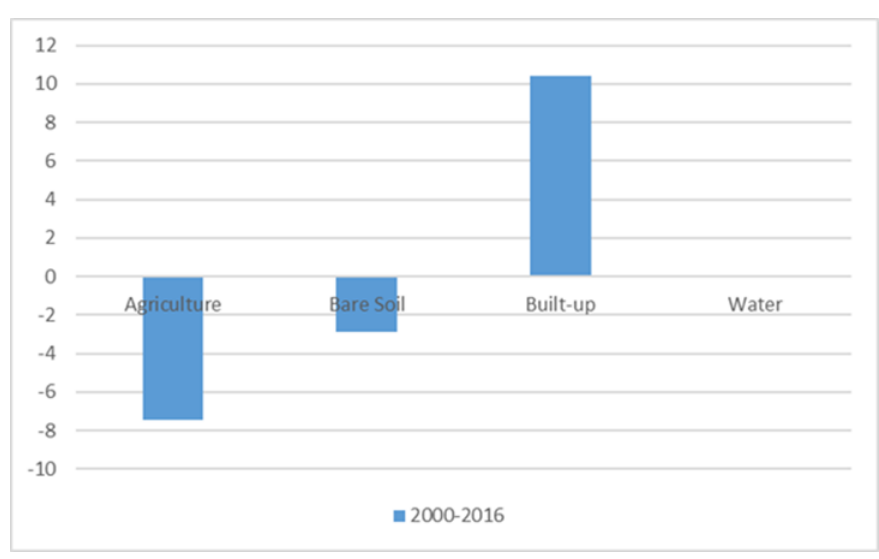

Figure 2 Area change during 2000-2016 


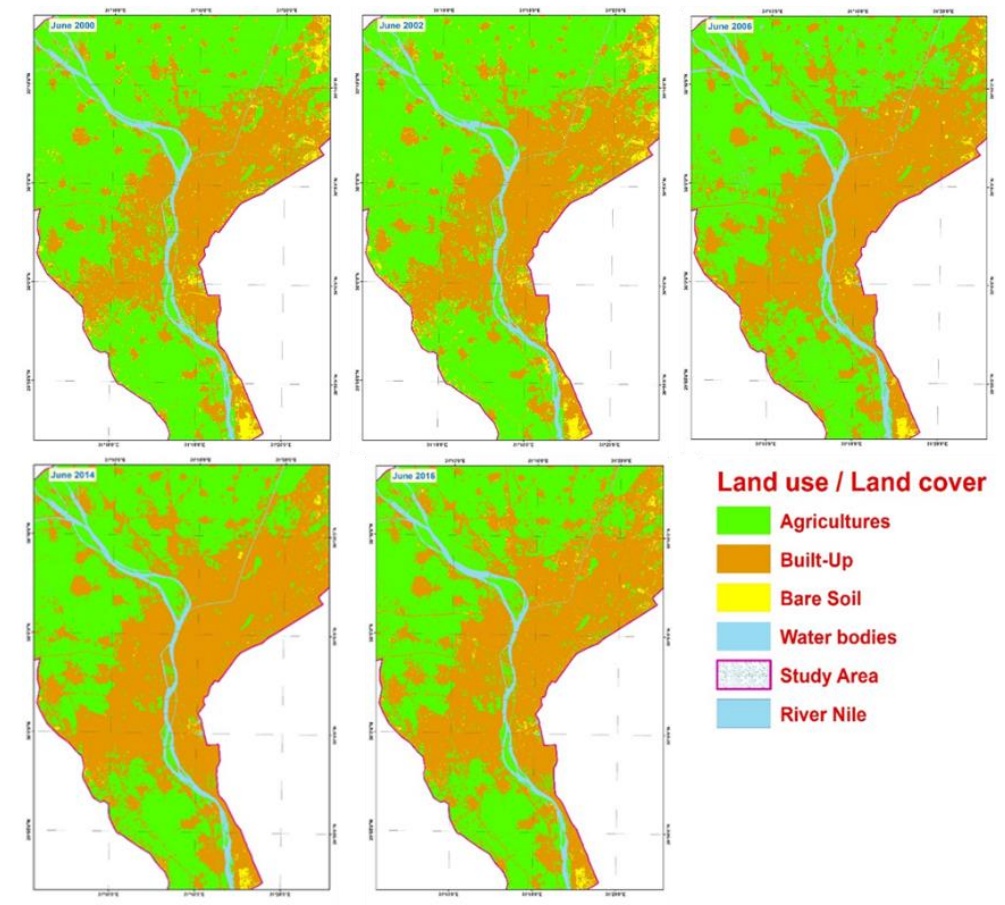

Figure 3 GCR changes during 2000-2016

\subsection{LULC Changes in the Three Governorates}

As for the obtained data, regarding the LUCL changes in the 3 governorates, they were analyzed and presented in tables, graphs so as maps (i.e. tables (3) to (7) together with figures (2) to (8)). These are discussed here, where they indicated that:

- $\quad$ Cairo Governorate is an urban governorate, where $86 \%$ of Cairo's land is urbanized; figure (4).

- Giza and Qalyubia are mixed governorates with urban area of $33 \%$ and $21 \%$, respectively, where water resources changes slightly over years.

- Changes in bare soil are visible in Cairo and Giza Governorates, where bare soil decreased in 2006 due to builtup zones; tables (3), (4), (5) and (6).

- $\quad$ Built up area in Cairo, Giza and Qalyubia increased by 15.9, 9.5 and 9.9\%, respectively, while the agriculture areas decreased by $8.7,6.4$ and $7.2 \%$, respectively.

- Cairo encountered the greatest land loss but agriculture loss was least affected.

- Cairo lost $17 \mathrm{~km}^{2}$ of agriculture land during 2000-2016 and gained $32 \mathrm{~km}^{2}$ of urban dwellings; table (3).

- Giza lost $47 \mathrm{~km}^{2}$ of its agriculture land and gained $70 \mathrm{~km}^{2}$ of its built-up spaces; table (5).

- Qalyubia lost $77 \mathrm{~km}^{2}$ of its agriculture areas and gained $97 \mathrm{~km}^{2}$ of its urbanized districts; table (7).

- In 15 years, GCR lost $141 \mathrm{~km}^{2}$ of its agricultural land and gained $199 \mathrm{~km}^{2}$ of its urbanization.

- GCR administrative development experienced great variability after 1952 revolution, where President Nasser build houses for all social classes and President Sadat suggested a privatized town planning for upper class (19).

- Home owners have workshop/store on the ground level and others use their roofs for poultry to generate income, despite the government efforts.

- $\quad$ Sprawl reached $20 \mathrm{~km}^{2}$ during 2000-2006, (20).

- In 1994, Ministry of Housing authorized selling of desert for investors to build building new communities, where 80 developments arose from deserts, (21). These developments lure the elite class, leaving lower classes in existing settlements.

- Giza and Qalyoubia sprawl followed a different patter. Giza and Qalyoubia sprawl surround the city. However, rural-urban settlements growth is portrayed.

Urban to rural population ratios reached equilibrium in 1970s, (6), where their growth exceeded metropolitan areas. 

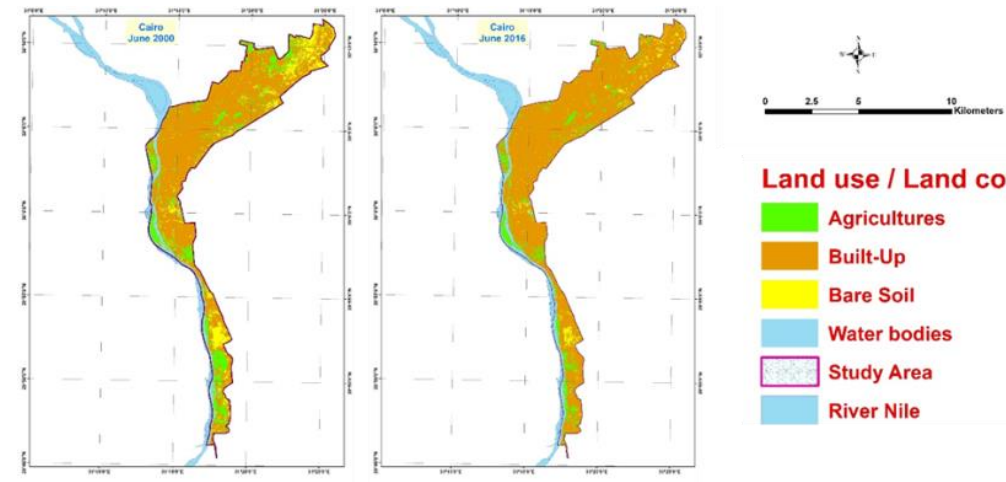

Land use / Land cover

Agricultures

Built-Up

Bare Soil

Water bodies

$\square$ Study Area

River Nile

Figure 4 Changes in Cairo Governorate 2000-2016
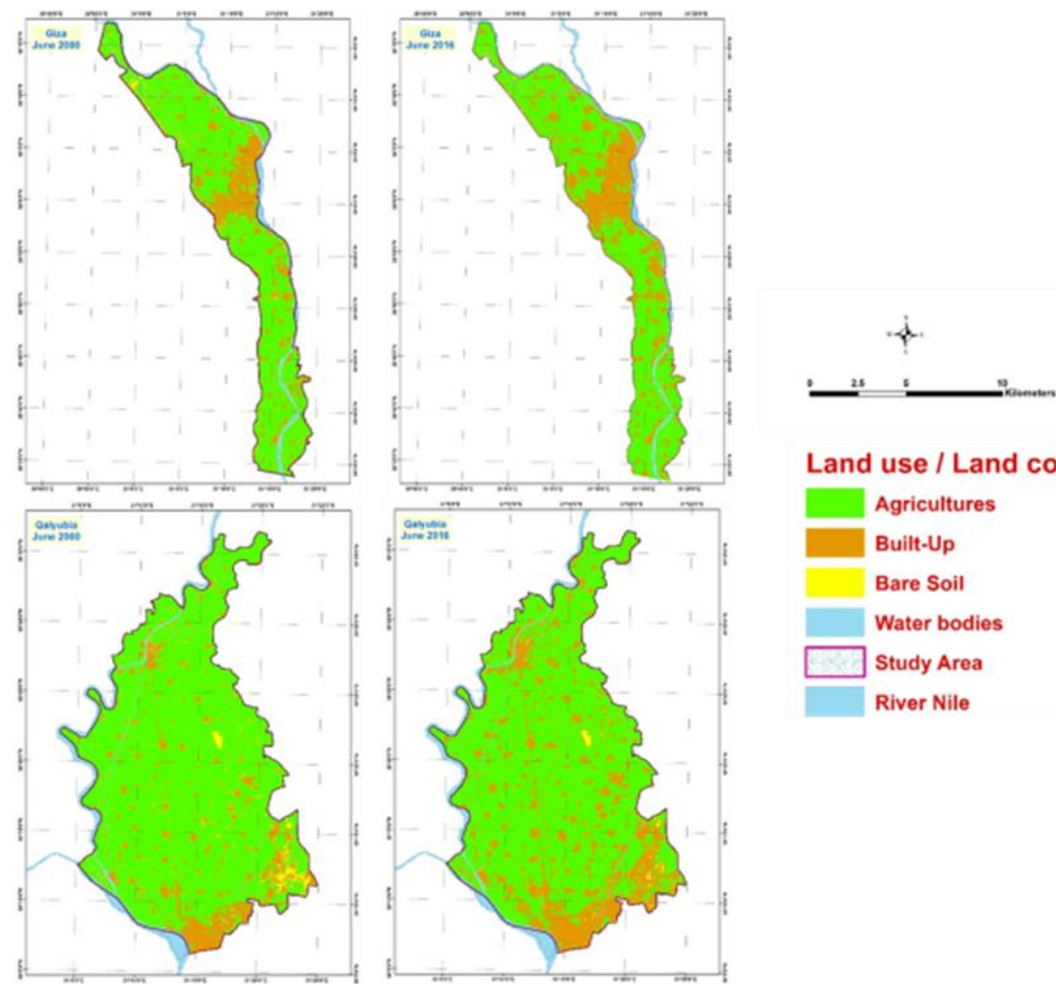

Land use / Land cover

Agricultures

Built-Up

Bare Soil

Water bodies

Study Area

River Nile

Figure 5 Giza and Qalyoubia changes during 2000-2016

Table 3 Cairo changes in area $\left(\mathrm{Km}^{2}\right)$

\begin{tabular}{|l|c|c|c|c|}
\hline Years & 2000-2002 & 2002-2006 & 2006-2014 & 2014-2016 \\
\hline Agriculture & -3 & -4 & -9 & -1 \\
\hline Bare Soil & 0 & -14 & -2 & 1 \\
\hline Built-up & 3 & 17 & 11 & 1 \\
\hline Water & 0 & 1 & 0 & -1 \\
\hline
\end{tabular}




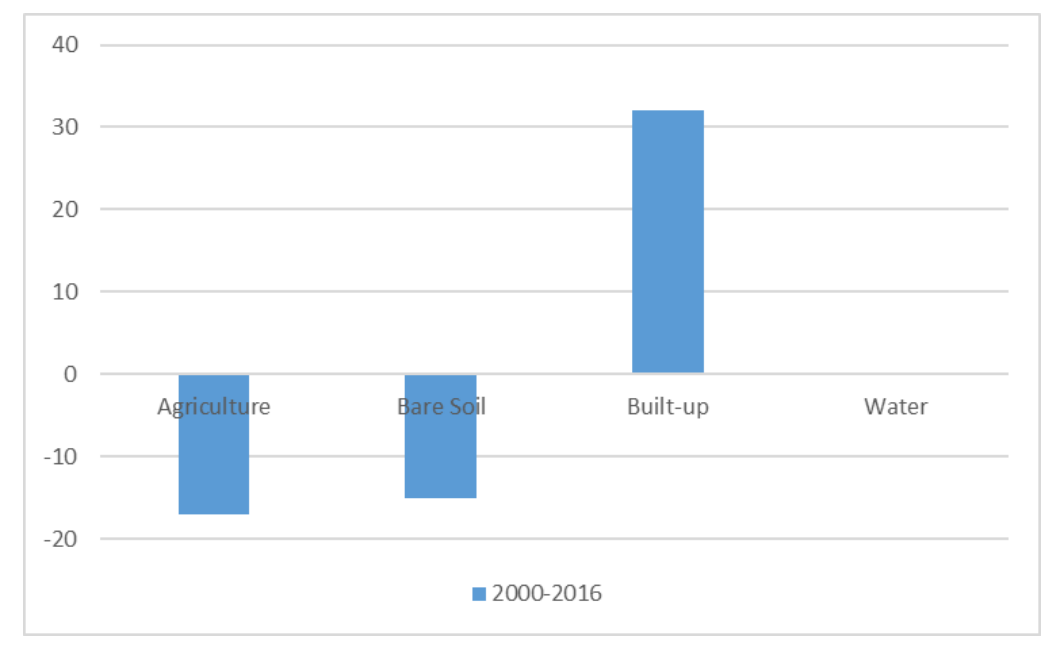

Figure 6 Cairo area changes in $\mathrm{Km}^{2}$ during 2000-2016

Table 4 Change in Cairo (\%)

\begin{tabular}{|l|c|c|c|c|}
\hline Years & $\mathbf{2 0 0 0 - 2 0 0 2}$ & $\mathbf{2 0 0 2 - 2 0 0 6}$ & $\mathbf{2 0 0 6 - 2 0 1 4}$ & $\mathbf{2 0 1 4 - 2 0 1 6}$ \\
\hline Agriculture & -1.53 & -2.04 & -4.59 & -0.51 \\
\hline Bare Soil & 0.00 & -7.14 & -1.02 & 0.51 \\
\hline Built-up & 1.53 & 8.67 & 5.61 & 0.51 \\
\hline Water & 0.00 & 0.51 & 0.00 & -0.51 \\
\hline
\end{tabular}

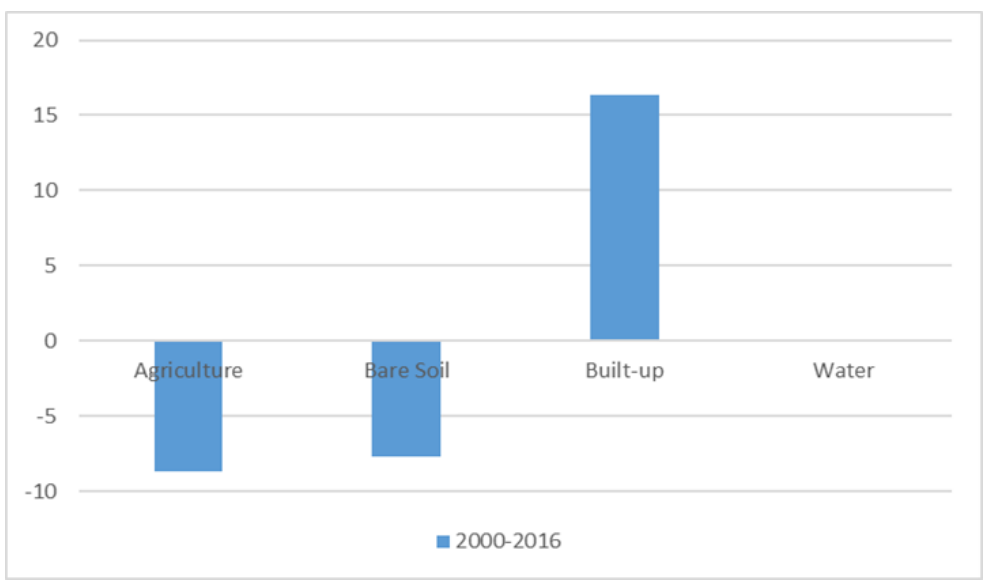

Figure 7 Change in Cairo during 2000-2016

Table 5 Area changes in Giza $\left(\mathrm{Km}^{2}\right)$

\begin{tabular}{|l|c|c|c|c|}
\hline Years & $\mathbf{2 0 0 0 - 2 0 0 2}$ & $\mathbf{2 0 0 2 - 2 0 0 6}$ & $\mathbf{2 0 0 6 - 2 0 1 4}$ & $\mathbf{2 0 1 4 - 2 0 1 6}$ \\
\hline Agriculture & -2 & -27 & -14 & -4 \\
\hline Bare Soil & -1 & -26 & 1 & 2 \\
\hline Built-up & 4 & 52 & 12 & 2 \\
\hline Water & -1 & 1 & 1 & 0 \\
\hline
\end{tabular}




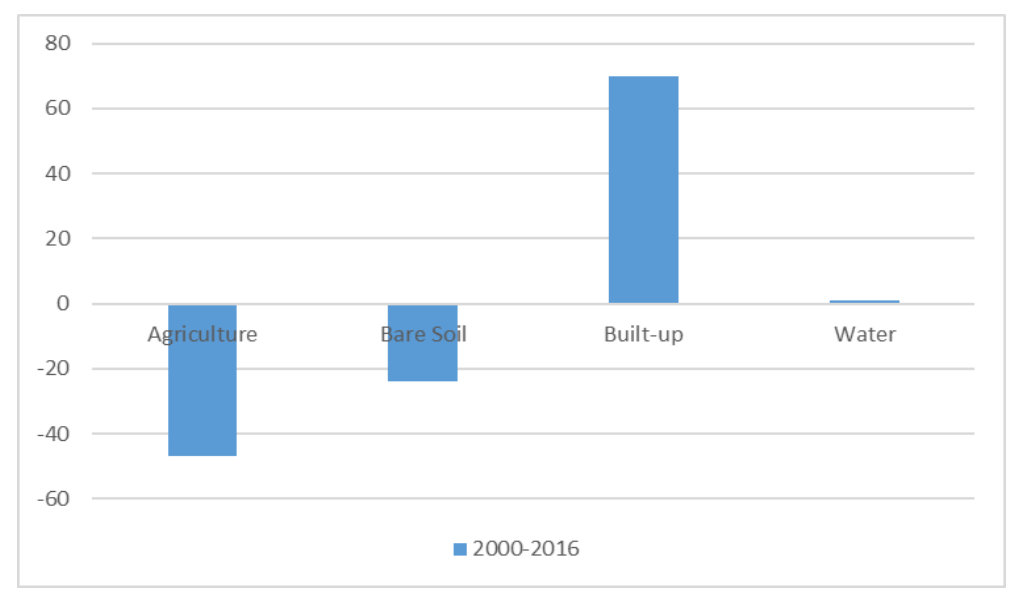

Figure 8 Area changes in Giza $\left(\mathrm{Km}^{2}\right)$ during 2000-2016

Table 6 Change in Giza (\%)

\begin{tabular}{|l|c|c|c|c|}
\hline Years & $\mathbf{2 0 0 0 - 2 0 0 2}$ & $\mathbf{2 0 0 2 - 2 0 0 6}$ & $\mathbf{2 0 0 6 - 2 0 1 4}$ & $\mathbf{2 0 1 4 - 2 0 1 6}$ \\
\hline Agriculture & -0.27 & -3.68 & -1.91 & -0.55 \\
\hline Bare Soil & -0.14 & -3.55 & 0.14 & 0.27 \\
\hline Built-up & 0.55 & 7.09 & 1.64 & 0.27 \\
\hline Water & -0.14 & 0.14 & 0.14 & 0.00 \\
\hline
\end{tabular}

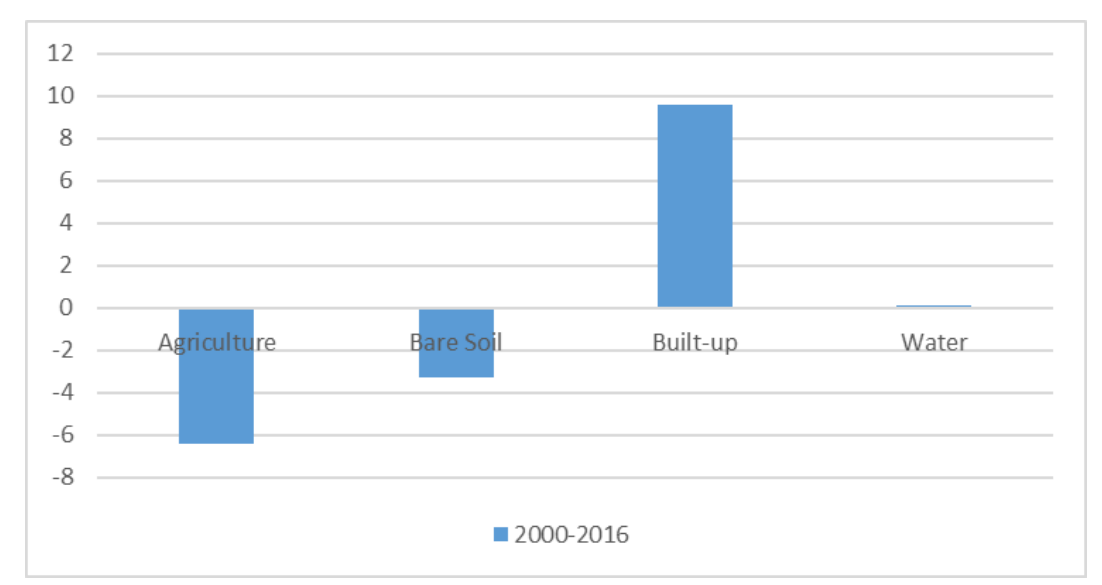

Figure 9 Change in Giza (\%) during 2000- 2016

Table 7 Area changes in Qalyoubia $\left(\mathrm{Km}^{2}\right)$

\begin{tabular}{|l|c|c|c|c|}
\hline Years & 2000-2002 & 2002-2006 & 2006-2014 & 2014-2016 \\
\hline Agriculture & -8 & -30 & -27 & -12 \\
\hline Bare Soil & 8 & -30 & -1 & 5 \\
\hline Built-up & 1 & 58 & 29 & 9 \\
\hline Water & -1 & 2 & -1 & -2 \\
\hline
\end{tabular}




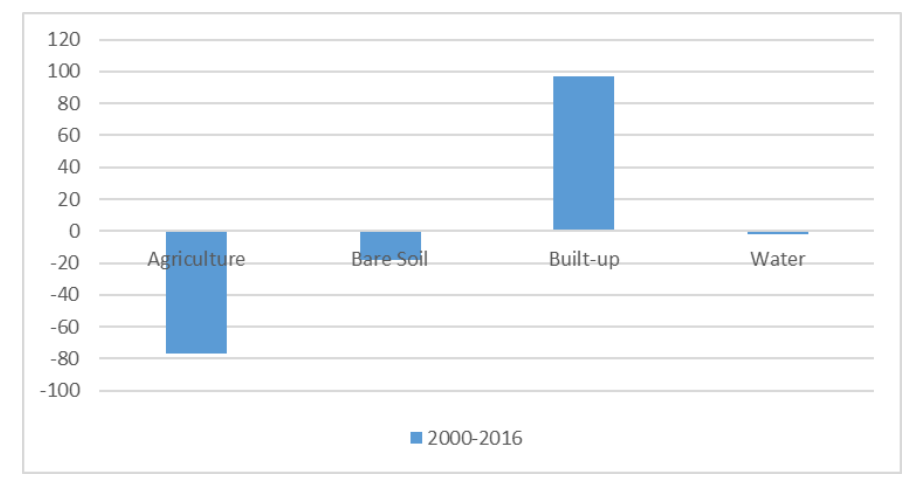

Figure 10 Area changes in Qalyoubia $\left(\mathrm{Km}^{2}\right)$ during 2000-2016

Table 8 Change in Qalyoubia (\%)

\begin{tabular}{|l|c|c|c|c|}
\hline Years & 2000-2002 & 2002-2006 & 2006-2014 & 2014-2016 \\
\hline Agriculture & -0.83 & -3.10 & -2.79 & -1.24 \\
\hline Bare Soil & 0.83 & -3.10 & -0.10 & 0.52 \\
\hline Built-up & 0.10 & 6.00 & 3.00 & 0.93 \\
\hline Water & -0.10 & 0.21 & -0.10 & -0.21 \\
\hline
\end{tabular}

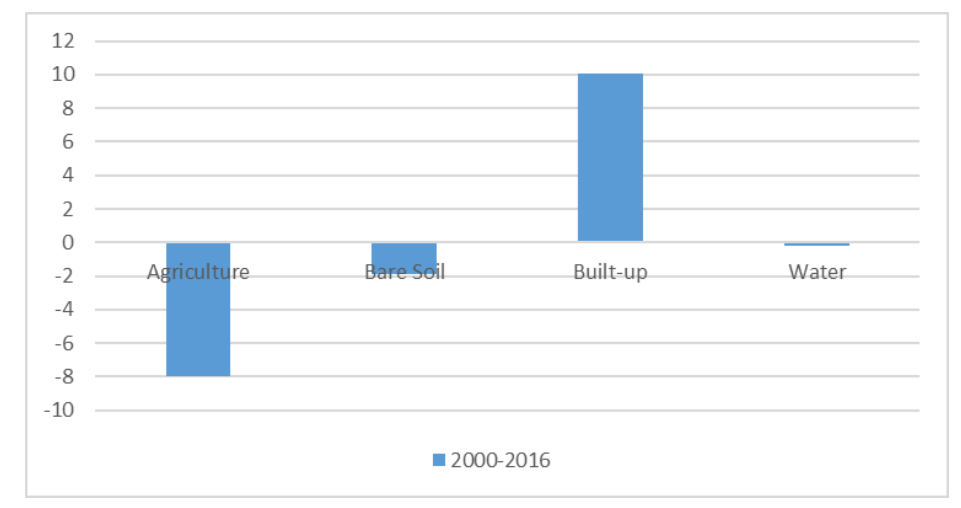

Figure 11 Change in Qalyoubia (\%)

\subsection{Verification}

Concentrating on the obtained data, regarding their verification, they were analyzed and presented in table (8). It is discussed here, where it flagged out that:

- An accuracy assessment was carried out that involved coordinates of different classes that ensured their accurate representation on maps. This was achieved based on fieldwork. This classic method is not applicable to long term reflective data, as land is continuously changing, which considers fieldwork to be impractical.

- However, Google Earth provides high-resolution images $30 \mathrm{~m}$ resolution through the Web. This data was implemented for class verification to ascertain class characteristics. Nevertheless, Google Earth has no pinpoint accuracy to identify the presence of water (e.g., River Nile, irrigation channels). Accordingly, digital globe highresolution imageries were acquired after year 2000.

- $\quad$ Output was geometrically aligned to test class's identification accuracy.

- Measures of classification accuracy were derived, where confusion matrices were implemented to reach an overall accuracy, commission errors, and Cohen's kappa statistic (22), where commission and omission errors were calculated for each LULC and an overall to all classes was estimated; table (9). The table indicated high 
accuracy over $90 \%$ for all years except 2006, where year 2006 image was obtained from Landsat-7 Enhanced Thematic Mapper Plus (ETM+).

Table 9 Accuracy assessment findings

\begin{tabular}{|l|l|l|l|l|l|}
\hline Items & $\mathbf{2 0 0 0}$ & $\mathbf{2 0 0 2}$ & $\mathbf{2 0 0 6}$ & $\mathbf{2 0 1 4}$ & $\mathbf{2 0 1 6}$ \\
\hline Total number of samples & 122 & 75 & 66 & 334 & 224 \\
\hline Total number of correct samples & 115 & 73 & 51 & 301 & 201 \\
\hline Total number of incorrect samples & 7 & 2 & 15 & 33 & 23 \\
\hline Overall Accuracy (\%) & 94 & 97 & 77 & 90 & 90 \\
\hline Kappa Coefficient & 0.91 & 0.91 & 0.66 & 0.82 & 0.81 \\
\hline
\end{tabular}

\subsection{Official Sprawl Data}

Referring to the obtained data, regarding official sprawl, they were analyzed and presented in table (10). They are elaborated here, where they highlighted that:

- Qalyoubia and Giza governorates were mostly affected by sprawl; table (10). Three marakiz were considered. They had the highest agriculture land loss (i.e. Qalyoub, Giza and Al-Khankah). However, data for Giza and other marakiz in Giza were burnt during the revolution.

- A comparison was held to Markaz Qalyoub and Al-Khankah, in terms of research results and the Ministry of Agriculture. This analysis flagged-out 50\% difference, table (11).

- The justifications might explain the differences between their order of magnitude (i.e. estimated and official). This reflected that if a farmer decided to leave farming, his land is not classified as agriculture. The owner might build on the land or sell it to 4 individuals with different usage visions. Accordingly, the government is does not have reliable information. Consequently, limited chances for governmental actions.

Table 10 Marakez with the highest rate of Sprawl

\begin{tabular}{|c|c|c|c|c|c|}
\hline & Governorate & Markaz & $\begin{array}{l}\text { Area of } \\
\text { Markaz } \\
\mathrm{Km}^{2}\end{array}$ & $\begin{array}{l}\text { Area of Encroachment } \\
\text { due to Urban Sprawl } \\
2000-2016 \mathrm{Km}^{2}\end{array}$ & $\begin{array}{l}\text { Percentage of Land } \\
\text { lost due to Urban } \\
\text { Sprawl 2000-2016 } \\
\%\end{array}$ \\
\hline 1 & Qalyoubia & Qelyoub & 121.86 & 15.46 & 12.69 \\
\hline 2 & Giza & Giza & 136.52 & 16.17 & 11.84 \\
\hline 3 & Qalyoubia & Al - Khankah & 149.85 & 17.34 & 11.57 \\
\hline 4 & Qalyoubia & $\begin{array}{l}\text { Awal Shobra } \\
\text { Al - Khaymah }\end{array}$ & 28.42 & 2.89 & 10.17 \\
\hline 5 & Giza & Al-Badrashin & 133.18 & 12.47 & 9.36 \\
\hline
\end{tabular}

Table 11 Comparison between the study's results and administrative data

\begin{tabular}{|l|c|c|}
\hline Location & $\begin{array}{l}\text { Official Government Data by } \\
\text { percentage of encroachment }\end{array}$ & $\begin{array}{l}\text { Data obtained from the study by } \\
\text { percentage of encroachment }\end{array}$ \\
\hline Qalyoub & 6.3 & 12.69 \\
\hline Al-Khankah & 4.5 & 11.57 \\
\hline
\end{tabular}

\subsection{Impacts of urban sprawl on irrigation water and agricultural activities}

The impacts of urban sprawl on agricultural activities and irrigation can be divided in two categories, The first relates to the direct impact of the violation on fertile farmland. The second is the indirect impact of urban sprawl detected on the remaining divided agricultural land and its associated agricultural activities, which leading to the following: 
- Water quality degradation, high levels of contamination in irrigation canals and a lesser extent in the groundwater led farmers to use groundwater for irrigation instead of using water canals.

- The Contaminated irrigation water required farmers to transform the type of crop into forage rather than edible crops.

- Many farm workers are pulling out of farming for other non-agricultural jobs, which has contributed to higher wages for farm workers and the scarcity of farm workers.

- Changes in the type of crop, reduce local farmers' contribution to meeting local food needs, which has led to higher food prices

\section{Conclusion}

Based on the above discussions, the following conclusions were deduced:

- The research results flagged out that there is a significant increase in the built-up area of the Greater Cairo Region of $11 \%$.

- The research findings identified that the land loss of land in the three governorates were changed over time, where the pattern of loss was portrayed in each governorate.

- The results focused on the most affected districts within the governorates, where a difference of $50 \%$. This highlighted a challenge to the government while dealing with sprawl.

- The change in LULC has a strong effect on irrigation water and agricultural activities.

Based on the above conclusions, the following recommendations were suggested:

- Accurate data should be available, as its absence hinders government action and procedures.

- Implement GIS and Remote Sensing, on free Landsat date, as tools for mapping land use and land cover changes in a fast and accurate manner.

- GIS and remote sensing technologies should be incorporated into policy in order to strengthen the process of land management.

\section{Compliance with ethical standards}

\section{Acknowledgments}

The author would like to thank the President of the National Water Research Centre (NWRC) and the GIS team at NWRC for their encouragement during the study. He also thank their families for their support during this unprecedented time to carry out this research.

\section{References}

[1] Jargowsky, Paul A. "Sprawl, Concentration of Poverty, and Urban Inequality." In Urban Sprawl: Causes, Consequences, \& Policy Responses. 2002; 39-72.

[2] UNDESA. Undesa World Urbanization Prospects. 2014.

[3] UN-HABITAT. Planned City Extensions : Analysis of Historical Examples. 2015.

[4] GOV.UK. "Planning Permission for Farms." 2018.

[5] McCarthy, Justin A. “Nineteenth-Century Egyptian Population.” Middle Eastern Studies. 1976; 12(3): 1-39.

[6] Salah Fadlalla. AN Economic Study about Encroachments on Agricultural Land and the RIVER Nile in the Egyptian Economy Dept. Agricultural Economics, Faculty of Agric., Assiut University. 2013.

[7] Central Agency for Public Mobilization and Statistics (CAPMAS). Statistical Yearbook - Population. Cairo. 2017.

[8] Moustafa, Doha Moustafa Ibrahim. “The Egyptian Urban Planning Institutional Framework." Technische Universitat Berlin. 2015.

[9] Central Agency for Public Mobilization and Statistics. 2017. "Population Census Results.” Egypt Yearbook. 2017.

[10] USGS. “GloVis.” 2017. 
[11] Coppin, P. et al. "Review ArticleDigital Change Detection Methods in Ecosystem Monitoring: A Review." International Journal of Remote Sensing. 2004; 25(9): 1565-96.

[12] Warner, Timothy A, David J. Campagna. Remote Sensing with IDRISI Taiga: A Beginner's Guide. Geocarto International Centre. 2009.

[13] Pringle MJ, M Schmidt, JS Muir. “Geostatistical Interpolation of SLC-off Landsat ETM+ Images.” ISPRS Journal of Photogrammetry and Remote Sensing. 2009; 64(6): 654-64.

[14] Eastman, J Ronald. IDRISI Andes Guide to GIS and Image Processing. Worcester: Clark Labs. 2006.

[15] Lillesand, Thomas M, Ralph W. Kiefer. Remote Sensing and Image Interpretation. 3rd ed. John Wiley \& Sons. 1994.

[16] Gao, Jay, and Yansui Liu. "Determination of Land Degradation Causes in Tongyu County, Northeast China via Land Cover Change Detection." International Journal of Applied Earth Observation and Geoinformation. 2010; 12(1): 9-16.

[17] Shalaby A. "Assessment of Urban Sprawl Impact on the Agricultural Land in the Nile Delta of Egypt Using Remote Sensing and Digital Soil Map." International Journal of Environmental Sciences Shalaby, A. International Journal of Environmental Sciences.

[18] Owojori A, H Xie. "Landsat Image-Based LULC Changes of San Antonio, Texas Using Advanced Atmospheric Correction and Object-Oriented Image Analysis Approaches." In 5th International Symposium on Remote Sensing of Urban Areas, Tempe: AZ. 2005.

[19] Ibrahim, Fouad N, Barbara. Ibrahim. Egypt: An Economic Geography. I.B. Tauris. 2003.

[20] Sutton, Keith, and Wael Fahmi. "Cairo's Urban Growth and Strategic Master Plans in the Light of Egypt's 1996 Population Census Results.” Cities. 2001; 18(3): 135-49.

[21] Salama, Rafik Khalil. ProQuest Dissertations Publishing "User Transformation of Government Housing Projects: Case Study, Egypt.” McGill University. 1995.

[22] Denis, Eric. "Cairo as Neo-Liberal Capital? From Walled City to Gated Communities." In Cairo Cosmopolitan : Politics, Culture, and Urban Space in the New Middle East, eds. Paul; Amar and Diane; Singerman. Cairo: The American University in Cairo Press.

[23] Congalton RG, Green K. Assessing the Accuracy of Remotely Sensed Data: Principles and Practices, Third Edition (3rd ed.). CRC Press. 2019. 